\title{
The Relationship between Motivational Intensity and Achievement: Implications for the Learning of English by Chinese Students
}

\author{
Yunbao Yang (Corresponding author) \\ Faculty of Education \\ La Trobe University (Bundoora Campus) \\ Melbourne 3083, Australia \\ E-mail: yangyunbaogeorge@hotmail.com \\ Huaying Zhang \\ Division of Foreign Exchange and Cooperation \\ Yunnan Agricultural University \\ Kunming 650201, China \\ E-mail: huayingzhang39@yahoo.com.cn \\ Jianghui Wang \\ Social Science Division, Dehong Teachers' College \\ Dehong 678400, Yunnan, China \\ E-mail: jianghuiwang1969@hotmail.com
}

\begin{abstract}
The correlation between motivational intensity and language learning has been explored to gain insights into why the learning of English has been poor in China. Hitherto, the learning of English as a foreign language in China has been taken for granted; unless effort is expended a measure of motivational intensity failure ensues. Success will only be achieved if learners understand the importance of learning English.
\end{abstract}

Keywords: Motivation, Intensity, Effort, Commitment, Achievement

\section{Introductory comment}

The fact that essentially all people learn to speak their native language without difficulty but most have difficulties in learning a second language has intrigued researchers for some time. Factors which impact on the acquisition of a second language will be considered in this paper.

\section{Ability or motivation}

Aptitude, intelligence and ability have been used synonymously and were the focus of research designed to understand learning achievement between the 1920s and 1950s. Over this period, research in this area was dominated by the studies of Gardner and Lambert $(1959,1972)$ and Gardner $(1985)$. They queried the importance of language learning ability or aptitude for language learning, given that people have no difficulty in learning to speak their native tongue; instead they raised the importance of motivation on the part of the learner and argued that motivation was a better predictor of the success of language learners. Later, Dörnyei (2001) highlighted the importance of effort on the part of the language learner, noting that in the classroom all have an equal chance to succeed in learning language and those who are successful expend effort in doing so. He also noted there was a potential negative side to emphasize language aptitude.

Further evidence for the importance of effort in achieving success in language learning was obtained by Hufton et al. (2002) who interviewed students aged 15 years from the United States of America, England and Russia. They found 
that the English and American students attributed success in language learning more to effort than ability and whereas the Russian students rated ability more highly, their concept of ability appeared to include a higher degree of effort. The researchers explained that the Russian students expended a great deal of effort in their learning and natural talent was the factor which distinguished the very top students from their peers.

\subsection{Motivation}

Pintrich and Schunk (1996) noted that the term motivation is derived from the Latin verb 'movere' (to move); in short, motivation is connected strongly with effort and actions. The term has a distinct meaning in the context of learning a second language as discussed below.

Gardner (1985) considered that motivation has three components, notably: "desire to achieve a goal"; "attitude"; and "effort'. He provided a simple but vivid description of motivation by pointing out that whilst many people desire to be millionaires, this goal is not achieved without expenditure of effort to achieve the goal. Clearly, whilst there may be interest in achieving an outcome there remains a need for action to realize the goal and effort should be expended in taking that action.

Motivation might exist in forms such as intensive mental activity. Given this, it is appropriate to consider that 'thinking and wishing' constitute the expenditure of effort. Indeed, many would-be-millionaires are thinkers not action takers.

Weinstein et al. (2000) provided similar features for motivation. In their terms, motivation has the key features of being: "goal directed"; "intentionally invoked"; and "effort demanding". Similarly, Dörnyei and Otto (1998) noted that people may have a variety of wishes, hopes and desires which remain "day dreams" unless the people are motivated to convert the dreams into realities. Dörnyei (2001) later described how desires are converted into goals then into intentions before accomplishment of the goal and finally the achievement is evaluated.

In the context of learning a language, motivation involves demonstrable learning activity accompanied by effort to attain the goal of learning the language. In the absence of these actions learning will remain a wish or desire. This process of transforming the desire into reality has been described as motivational intensity (Gardner, 1985) - see below.

\subsection{Motivational intensity and language learning}

Krashen (1976) pointed out that success in learning a second language requires more than long-term exposure; instead active involvement is necessary. More recently, Pintrich and Schunk (1996) considered that persistence is a common measure of motivation and Zhu (2002) claimed that persistence is crucial for success in learning a foreign language and further commented that the learner should be courageous and determined in order to be successful. Previously, Zhang (2000) had noted that confidence underpins determination and once confidence is established active participation in learning a foreign language will occur and perseverance will be followed by successful achievement.

These observations of Zhang (2000) and Zhu (2002) on perseverance and determination in learning a foreign language are consistent with the practices used for the learning of English in China. As had been noted by Schunk, (1991), motivation can influence what, when and how learning occurs. In China, high learning achievement generally is attributed to diligence and hard work which are synonymous terms in Chinese (Yang, 2004). The belief, in China, that academic performance is influenced principally by hard work has been demonstrated by Hau, and Salili (1996) and Hou (2004).

Deci and Ryan (1985), in proposing the self-determination theory, noted that an individual displays intrinsic motivation when engagement in a task occurs primarily because it is an enjoyable or fulfilling activity. 'Engagement' is taken to be the intrinsic attraction an individual exhibits as well as the commitment. In contrast, extrinsic motivation occurs when the individual undertakes a task to gain an award or to avoid punishment. For example a child who works hard on a school project because it is considered to be interesting is regarded as being intrinsically motivated whereas a student who studies hard because of the prospect of a reward for achieving high marks (grade) is considered to be extrinsically motivated.

In considering motivational intensity, the different types of motivation should be considered. Gardner and Lambert $(1959,1972)$ and Gardner (1985) focussed on integrative motivation, apparently considering that it was a strong indicator of learning success. Even so, they did not overlook the importance of effort which equates to intensity. They considered integrative motivation to be the interaction with and willingness to use the language being learnt. In other words, learners were expected to experience intense communication with native users of the language.

From the above, persistence and determination are key determinants of success in learning a second language. Learning a second language is different from learning other skills and learners need to maintain a steady pace in their learning. Persistence is important not only because learners will encounter unfamiliar and even challenging situations; they will not always achieve immediate success. Those who demonstrate persistence and determination will overcome difficulties they face in the short term but also in the long run and ultimately will be successful. 


\subsection{Goal Oriented Theory}

It is equally important to discuss goal oriented theory._Over the past two decades goal orientation theory has become increasingly influential and it is now one of the most important perspectives in motivation for achievement (Patrick, 2004; Urdan, 2004). As pointed out by Molden and Dweck (2000), examination of the goals set by individuals may enable a greater insight to be gained of the different views on the means of achievement, the reasons for success or failure and the importance to the individual of achieving goals set. Whilst it is usual to place emphases on goals set in athletic and work environments it is equally valid to measure goals in learning environments (Alderman, 1999).

Oxford and Shearin (1994) observed that the setting of goals can be of considerable importance in terms of stimulating motivation for the learning of a second language because many major goals are long-term; for example, completing a degree or obtaining a good job. Students who engage in a task, expend effort and persist are more likely to achieve at a high level than those who do not (Pintrich and Schrauben, 1992; Schunk, 1991). Elliot et al. (2005) considered that 'attribution theory' has highlighted the importance of effort for achievement and concluded that in both Western and Eastern cultures hard work is considered widely to be morally desirable and the key to successful achievement.

As mentioned above, Dörnyei (2001) described the process by which wishes or desires are transformed into goals then converted to intentions which ultimately are enacted leading to achievement, or otherwise, of the goal. The final step is the evaluation of the achievement. Later, Dörnyei (2005) identified motivation, in the context of acquiring a second language, as comprising three stages which he listed as, the 'pre-actional', 'actional' and 'post-actional' stages and effort was the key to achievement. Action requires effort and this constitutes motivational intensity. In expressing this view, Dörnyei (2005) provided a more direct theory than that proposed by Gardner (1985) who considered attitude to be of key importance; Dörnyei (2005) did not.

Motivation requires activity, either physical or mental or more likely both. Physical activity entails effort, persistence and other overt actions whereas mental activity includes such cognitive actions as planning, rehearsing, organizing, monitoring, making decisions, solving problems and assessing progress. Students engage in activities with the view to attaining goals (Pintrich and Schunk, 1996) and those who choose to engage in a task, expend effort and persist are likely to achieve at a higher level than those who do not ( Schunk, 1991)

Hidi (2000) suggested that where activities are complex and of lengthy duration it may be necessary to have a combination of intrinsically appealing components as well as extrinsic rewards to maintain the engagement of students. This is because a single source such as intrinsic motivation may be exhausted when students progress from one level to the next. Care needs to be exercised when considering how strong intrinsic motivation will be in a context such as China where English is not a communicating tool in social life. Therefore, extrinsic factors may be important for facilitating the learning process and ultimately achievement. This is likely to be the case for the learning of a second language.

\subsection{The relationship between motivational intensity and achievement in the Chinese context}

Due to the teachings of Confucious, Chinese people place considerable emphasis on the malleability of humans. They believe that achievement is possible if they work hard, regardless of their current level of ability. Whilst not denying the existence of differences in innate levels of ability the differences are de-emphasized. Instead, innate ability is considered to be a determinant of the rate of attainment and effort is considered to be the key factor for ultimate level of achievement (Chen et al., 1996).

In China, children are reared in an environment where effort, endurance and hard work are emphasized (Yang, 1986). They are taught to work hard even when the probability of success is very low. There are many Chinese proverbs alluding to the benefits of hard work; for example: " if one keeps on grinding one can turn an iron pillar into a needle"; and "if one has the perseverance one can even remove a hill, (the symbolic obstacle) by carrying away the sand with baskets' - see Chen et al. (1996). It is not difficult to appreciate how it is that diligence is a highly regarded trait in people in China. The intensity and effort expended here in accomplishing a task is considered to be similar to the 'actional' and commitment features of motivation discussed above. These cultural characteristics are commonly shared in Confucian China.

A similar view prevails in Japan as pointed out by Hess and Azuma (1991) who noted that Japanese students display diligence and receptiveness which contrasts with the more familiar concepts of intrinsic and extrinsic motivation which prevail in the United States of America, and elsewhere in the Western World. Indeed, Hess and Azuma (1991) considered that Western students lack the sense of diligence observed in Asian students and need to be motivated extrinsically to increase the attraction of tasks and the classroom. This is not necessary in the Asian classroom where students are expected to work hard to achieve the learning goals set for them.

The reason why so much effort is invested in education in China is the high status which derives from education. In traditional thinking, children are taught that all jobs, except learning, have a low status (Hau et al., 1996). Education is 
believed to be important not so much from the aspect of social hierarchy but because it leads to better development of the whole person (Ho, 1981; Mordkowitz and Ginsburg, 1987).

Many writers have drawn attention to the Asian belief that success stems from effort rather than ability whereas Westerners consider that ability is the key to success and failure is due to a lack of ability (Holloway, 1988; Hess and Azuma, 1991; Chen et al., 1996). Hau and Salili, (1996) reported that students at secondary school in Hong Kong considered that their academic success was due to the following factors, in order, of importance; effort; interest in study; study skill; mood and finally ability. It is possible to exert some control over the first four of these factors, but not ability which is regarded by Western students to be the most important factor. It is noteworthy that Clifford (1986) pointed out that strategy attributions such as study skills can be valuable for redeeming poor performance.

Chinese parents strongly emphasize to their children that hard work will lead to the development of interest and study skills which in turn result in the cultivation of interest and subsequently improvement of ability. Thus, in the minds of Chinese parents, interest and ability are equally controlled, just as study skills and effort are. This is quite different to Western thinking where individualism is stressed and it is thought that interest should come naturally (see Hau and Salili (1996).

Chinese students are taught to be responsible for their own academic performances; it is considered that failure stems from laziness and success follows hard work (see Hau and Salili 1996). Students who are academically motivated believe that if they study diligently they will attain good grades (marks). Given that they value high grades, they are likely to study hard and in so doing confirm their expectations (see Pintrich et al., 1996).

The belief in China that effort is critical for learning success derives from the high degree of involvement of parents and other family members in the learning of the students. Parents set high standards for their children and commit considerable time to the supervision and provision of assistance with the school work of their children (Yang, 2004). The students are encouraged to learn by drill ('rote learning') because of the belief that interest in study, which may be totally lacking initially, will be developed through repetitive work (Hau et al., 1996).

\subsection{Concluding Comments}

Learners of a second language will not be successful unless they are motivated and display motivational intensity. Motivation may occur intrinsically but it is more likely that extrinsic motivation precedes this. Persistence and determination are important characteristics for success in learning a language. Learners of a second language become exposed to a culture with which they are not familiar, so they need to be persistent, not only because they will be exposed to different, even challenging situations (as noted above), but because many will fail to learn the language. As note by Naiman et al. (1978), high achieving language learners are not necessarily those for whom language is acquired very easily; instead they have persevered overcoming difficulties and frustration and after trial and error attain a satisfactory level of achievement.

In China, whilst there is a belief that hard work is the key to success in achieving a set task (for example learning of a second language), motivation for undertaking the task often is lacking or poor. Given this it will be necessary to devise procedures for motivating students if success is to occur in the teaching and learning of English language. Once students have the wish to learn (viz. motivation) there is the need to take action to achieve the desired outcome. Given the prevailing culture for hard work in China the latter is expected to occur. This achievement will not be made if actional intensity is absent.

It is important to develop and nurture interest in learning English because ultimately the English language will be crucial for the Chinese people. English learners should be aware of why it is important to learn English; in particular the benefits they will derive from learning the language. Although the inability to use English language prevents many people from achieving many things, this often is not clear to students of the language. An awareness of the importance of English language is the starting point for motivation to learn the language.

\section{References}

Alderman, M. K. (1999). Motivation for achievement: Possibilities for teaching and learning. Mahwah, NJ: Lawrence Erlbaum.

Chen, C. S., Lee, S. Y., \& Stevenson, H. W. (1996). Academic achievement and motivation of Chinese students. In Lau, S. (Ed.), Growing up the Chinese way: Chinese child and adolescent development (pp: 69-91). Hong Kong: The Chinese University Press.

Clifford, M. M. (1986). The comparative effects of strategy and effort attributions. British Journal of Educational Psychology, 56, 75-83.

Deci, E. L., \& Ryan, R, M. (1985). Intrinsic motivation and self-determination in human behaviour. New York: Plenum. 
Dörnyei, Z. (2001). Motivational strategies in the language classroom. Cambridge: Cambridge University Press.

Dörnyei, Z. (2005). The psychology of the language learner: individual differences in second language acquisition. New Jersey: Lawrence Erlbaum Associates, Inc., Publishers.

Doryei, Z., \& Otto, I. (1998). Motivation in action: A process model of L2 motivation. Working Papers in Applied Linguistics, (Thames Valley University, London). [Online] Available: http://eprints.nottingham.ac.uk/archieve/000000/Motivation_in_action.pdf

Elliott, J. G., Hufton, N. R., Willis, W. \& Illushiin, L. (2005). Motivation, engagement and educational performance: International perspectives on the contexts for learning. New York: Palgrave Macmillan.

Gardner, R. C. (1985). Social psychology and language learning: The role of attitudes and motivation. London, Ontario: Edward Arnold.

Gardner, R. C., \& Lambert, W. E. (1959). Motivational variables in second language acquisition. Canadian Journal of Psychology, 13, 266-272.

Gardner, R. C., \& Lambert, W. E. (1972). Attitudes and motivation in second - language learning. Rowley, Massachusetts: Newbury House Publishers.

Hau, K. T., \& Salili, F. (1996). Achievement goals and causal attributions of Chinese students. In Lau, S. (Ed.), Growing up the Chinese way: Chinese child and adolescent development (pp:121-145). Hong Kong: The Chinese University Press.

Hess, R. D., \& Azuma, M. (1991). Culture support for schooling: Contrasts between Japan and the United States. Educational Researcher, 20 (9):2-8.

Hidi, S. (2000). An interest researcher's perspective: The effects of extrinsic and intrinsic factors on motivation. In C. Sansone and J. M. Harachiewicz (Eds.), Intrinsic and extrinsic motivation: The search for optimal motivation and performance. New York: Academic Press.

Ho, D. Y. F. (1981). Traditional patterns of socialization in Chinese society. Acta Psychologica Taiwanica, 23 (2): 81-95.

Holloway, S. D. (1988). Concepts of ability and effort in Japan and the US. Review of Educational Research, 58: 327-345.

Hou, L. P. (2004). Emphasizing students' emotion to improve their English learning. Foreign Language Teaching in Schools, 3 (165), 35-37.

Hufton, N. R., Elliott, J. G., \& Illushin, L. (2002). Educational motivation and engagement: Qualitative accounts from three countries. British Educational Research Journal, 28, 265-289.

Krashen, S. D. (1976). Formal and informal linguistic environments in language learning and language acquisition. TESOL Quarterly, 10, 157-168.

Molden, D. C., \& Dweck, C. S. (2000). Meaning and motivation. In C. Sansone \& J. M. Harachiewicz (Eds.), Intrinsic and extrinsic motivation: The search for optimal motivation and performance. New York: Academic Press.

Mordkowitz, E. R., \& Ginsburg, H. P. (1987). Early academic socialization of successful Asian-American college students. The Quarterly Newsletter of the Laboratory of Comparative Human Cognition, 9 (2): 85-91.

Oxford, R., \& Shearin, J. (1994). Language learning motivation: expanding the theoretical framework. The Modern Language Journal, 78, 12-28.

Patrick, H. (2004). Re-examing classroom mastery goal structure. In P. R. Pintrich \& M. L. Maehr (Eds.), Motivating students, improving schools: The legacy of carol midgley. London: Elsevier.

Pintrich, P. R., \& Schunk, D. H. (1996). Motivation in Education. NJ: Prentice-Hall, Inc. A Simon \& Schuster Company, Englewood Cliffs.

Pintrich, P. R., \& Schunk, D. H. (1996). Motivation in Education. NJ: Prentice-Hall, Inc. A Simon \& Schuster Company, Englewood Cliffs.

Schunk, D. H. (1991). Self-efficacy and academic motivation. Educational Psychologist, 26, 207-231.

Urdan, T. (2004). Can achievement goal theory guide school guide school reform? In P. R. Pintrich \& M. L. Maehr (Eds.), Motivating students, improving schools: The legacy of carol midgley. London: Elsevier.

Weinsten, C. E., Husman, J., \& Dierking, D. R. (2000). Self-regulation interventions with a focus on learning strategies. In M. Boekaerts, P. R. Pintrich, \& M. Seidner (Eds.), Handbook of self-regulation (pp. 727-747). San Diego: Academic Press. 
Yang, K. S. (1982). Causal attributions of academic success and failure and their affective consequences. Acta Psychologica Taiwanica, 24 (2): 65-83.

Yang, Y. B. (2004). Characteristics of good English learners - urban key senior secondary school students learning English in Yunnan - China. Unpublished MA thesis. Melbourne: La Trobe University.

Zhang, Z. D. (2000). Theories and schools of foreign language teaching methodology in China. Beijing: Science Publishing Press.

Zhu, C. (2002). Psychology in foreign language teaching and learning. Shanghai: Shanghai Foreign Language Education Press. 